6. Smith, Priestley.-Summary in Elliot's "Treatise of glaucoma," pp. 116-18, Churchill. 1922.

Also "The pathology and treatment of glaucoma." Churchill, 1891. Also The Ophthal. Rev., Vols. XIX-XXI, 1910-12.

7. จ. Helmholtz, H. -Arch. f. Ophthal., Bd. I, H. 2, S. 39, 1855.

8. Grönholm, V.-A rch. f. Augenheilk., Bd. LXVI, H. 1, S. 346, 1910.

9. Heine, L.-Arch.f. Ophthal., Bd. LXIX, H. 1, S. 1. 1899.

10. Thomson, A.-The Ophthalmoscope, Vol. IX, p. 470, 1911.

11. Küsel.-Klin. Monatsbl. f. Augenheilk., H. 2, S. 44, 1906.

12. Seefelder, R.-Graefe-Saemisch, Handbuch d. ges. Augenheilk., Bd. I, Abt. 1, Kap. 2, Anhang. SS. 26-28, Fig. 10, 11, 1910.

13. Koster, W. -Arch.f. Ophthal., Bd. XLI, H. 2, S. 30, 1895.

14. Heerfordt, C. F.-Arch. f. Ophthal., Bd. LXXVIII, H. 3, 1911; and Bd. LXXXIII, H. 1, 1912.

15. Berner, O.-Brit. Jl. of Ophthal., Vol. X, p. 425, 1926.

16. Salzmann, M-Loc. cit., pp. 177-8.

17. Herbert, H.-Trans. Ophthal. Soc. U.K., Vol. I, p. 344, 1925.

18. Troncoso, U.-A mer. Jl. of Ophthal., Vol. VIII, p. 448, 1925.

19. Raeder, J. G., quoted by O. Berner.-Brit. Ji. of Ophthal., Vol. X, pp. 434-5, 1926.

20. Grönholm, V.-Lot. cit.

21. Henderson, Thomson-Ophthal. Rev., Vol. XXVI, p. 255, 1907.

22. Ranvier, L.-Cornée. 1881. Leçons de l'Anatomie gén. faites au collége de France, année 1878-9 Paris.

23. Salzmann, $\mathbf{M}-$ Loc. cit., p. 111.

24. Barfurth, D.-Quoted in Quain's Anatomy, Vol. II, pt. i, p. 195. 1912.

25. Stutzer, H. G-Arch. f. Ophthal., Bd. XLV., S. 328, 1898.

26. Prokopenko.-Arch.f. Ophthal., Bd. LV., S. 117, 1903.

\title{
AN ENQUIRY INTO THE OCCURRENCE AND EFFECTS OF VOMITING AFTER CATARACT EXTRACTION
}

\author{
BY \\ FRANK W. LAW \\ SENIOR HOUSE SURGEON, MOORFIELDS EYE HOSPITAL
}

IT would seem at first sight difficult to assemble any concrete facts concerning the causes and effects of vomiting after cataract extraction, but it is here my intention to endeavour to indicate the main factors operating in the causation of this phenomenon-one which may at best be described as an ever-present nuisance, and at worst may be a catastrophe spoiling an operation otherwise perfect in all respects-and by following up closely the relevant cases, to gauge the extent of the deleterious effects caused by it.

In the first place it would be appropriate to give details of the routine treatment of cataract patients at Moorfields Eye Hospital. These patients are admitted two days before operation, and a conjunctival swab is taken for bacteriological examination; an aperient is given on the day of admission, and on the following day, if necessary. The eye is irrigated with boric acid lotion twice a day; the 
night before operation the skin of the parts of the face adjacent to the eye to be operated upon is cleansed with ether soap and mercury perchloride, 1 in 10,000. Drops are or are not used in the eye immediately before operation according to the wishes of the operating surgeon-in some cases homatropine and cocaine, in some atropine; in all cases the lashes are cut short in the outer half.

After operation both eyes are covered for 24 hours by two pads and a " Moorfields Eye Bandage,"' when the first dressing is done: after that the unoperated eye is left uncovered. The patient is kept in bed strictly supine; any kind of movement is discouraged, that of the head being expressly forbidden. The hands are tethered at night for the first week to prevent any possibility of the eye being touched during sleep. The diet for the first three days is either very light or actually fluid in nature; the bowels are allowed to remain confined for three days, an aperient being given on the third night after operation. If the case is straightforward the patient sits up one week after operation, gets out of bed on the tenth day and leaves hospital on the fourteenth.

Should vomiting occur every effort is made by the nursing staff to restrict movement on the part of the patient; the head is firmly held while vomiting is going on, and the patient is instructed to make as little effort as possible. The usual medicinal measures to allay vomiting are adopted, and the diet is adjusted.

The operations take place at a time (according to which surgeon is operating) between $10.30 \mathrm{a} . \mathrm{m}$. and $1 \mathrm{p} . \mathrm{m}$. In the ordinary way the only food a patient would have had on the day of operation is one cup of tea and two thin slices of bread and butter at about 5.45 a.m. Some alteration in this dietary has been experimented with, of which mention will be made later.

The only cases with which one is here concerned are cases of uncomplicated senile cataract. During the period Auguist 1, 1928, to January 8, 1929, 141 such cases were operated upon at this hospital, and in 17 of those cases operation was followed by vomiting. A list of these 17 cases follows, which includes brief notes of the type of operation performed, the patient's behaviour, and other details. In each case local anaesthesia (cocaine, 4 per cent.) was employed.

1. Female, aged 68 years. Urine normal. Left extraction with complete iridectomy, September 19, 1928. Behaved fairly well at operation; mental stability doubtful afterwards, noisy and restless. Complained of nausea at 8.30 p.m. on day of operation; vomited early morning (once) and evening (once) September 20, 1928. Pillars were a little up afterwards ; on discharge, pillars free. Duration of stay, 4 weeks.

2. Female, aged 75 years. Urine normal. Right extraction, v. Graefe iridectomy, vitreous loss ++ ; pillars and vitreous left up; 
August 9, 1928. Behaviour at and after operation was appailling; she squeezed hard all the time, and was very restless afterwards. Vomited once August 13, 1928-pillars were found prolapsed; vomited again August 16, 1928. Prolapse abscission under general anaesthetic, August 20, 1928. Bead of vitreous persisted in wound for 9 weeks. Was in hospital for 10 weeks after operation. Has recently had iridotomy performed.

3. Female, aged 76 years. Urine normal. Left extraction with complete iridectomy, September 8, 1928. Behaviour was good, though there was some coughing after operation. Vomited twice on evening of operation, and once at $3 \mathrm{a} . \mathrm{m}$. on morning of following day. Pillars were a little up as a result; there was a hyphaema on the 13th and another on the 20th. On discharge, the pillars were still up a little. Total time 3 weeks.

4. Female, aged 78 years. Urine contained sugar +++ . Right extraction with complete iridectomy, August 27, 1928. The patient was unintelligent but behaved well at operation; she was rather restless two days afterwards. She vomited from the afternoon of September 1, 1928, at intervals until the morning of September 2,1928 ; no prolapse occurred. Though treated with insulin and kept on a sugar-free diet, the patient died in diabetic coma on the 2nd.

5. Female, aged 66 years. Urine normal. Right extraction with complete iridectomy (done with the v. Graefe knife during incision) August 7, 1928, with irrigation of the anterior chamber. She behaved fairly well at operation and well afterwards. Vomiting occurred once on the evening of operation, and the iris prolapsed; abscission was done on the following day. The patient's vision in the operated eye on discharge, 21 days after operation, was (corrected) 6/9.

6. Male, aged 74 years. Urine normal. Right extraction with peripheral iridectomy, August 14, 1928, The patient behaved well but complained of sleeplessness and lack of appetite before operation. There was a very severe haematemesis on the day following operation at $4 \mathrm{p} . \mathrm{m}$. and 3 more in the late evening (there was a history of ? gastric ulcer). No ill-effects to the eye; left hospital in 20 days with corrected vision $6 / 6$.

7. Female, aged 56 years. Urine normal. Left extraction with peripheral iridectomy October 5, 1928; behaved very well. Complained of a "bilious attack" on the 14th and vomited twice. There were no ill-effects, and the patient left in the routine time with vision $6 / 36$.

8. Male, aged 61 years. Urine normal. Morgagnian cataract. Left extraction with complete iridectomy, October 8, 1928; behaviour good. Vomited 7 a.m. the following day; no ill-effects. Left in routine time with vision $6 / 36$, much lens matter being present. 
9. Female, aged 53 years. Urine normal. Left simple extraction, with conjunctival bridge, October 10, 1928. Behaved well; vomited at 8.30 p.m. on the day of operation; no ill-effects were noted, though the patient was myopic $20 \mathrm{D}$. Left in routine time with vision $6 / 36$.

10. Female, aged 76 years. Urine normal. Right simple extraction, October 26, 1928. Behaved very badly at operation and was very restless afterwards. Vomited 1.30 p.m. on the following day; no ill-effects. Considerable mental disturbance ensued; there was a small hyphaema on the 29th. Left in routine time, seeing fingers at 2 metres with a +13 D.Sph., accurate refraction being impossible.

11. Female, aged 65 years. Urine normal. Right extraction with peripheral iridectomy, October 25, 1928; behaviour good at operation, though mental disturbance followed. Vomited on October 28,1928 , one hour after $\frac{1}{6}$ gr. of morphia had been given, and frequently during the night; again three times on the following day. No ill-effects ; left hospital in 17 days with vision 6/24 (much lens matter).

12. Female, aged 83 years. Urine normal. Right extraction with peripheral iridectomy, October 25, 1928; behaved well. At 2 p.m. on the following day the patient sat up in bed and vomited; she also vomited twice on the 30th. The pupil was a little drawn up; keratic precipitates appeared in the eye and persisted until after discharge; she left hospital in 22 days with vision " hand movements." The eye eventually did well.

13. Female, aged 78 years. Urine normal. Left extraction with peripheral iridectomy, November 17, 1928; behaved well. Vomited the day after, once; no ill-effects. Left hospital in routine time.

14. Male, aged 60 years. Urine normal. Right extraction with complete iridectomy, November 23, 1928 ; behaviour was very bad indeed at operation, the patient squeezing hard. He vomited a large volume of dark-coloured fluid (resembling altered blood) on the following day at 12.30 p.m.; from 9 p.m. onwards he vomited at intervals for 4 hours. No ill-effects; left in routine time with vision $6 / 12$.

15. Male, aged 59 years. Urine normal. Left simple extraction, November 27, 1928; behaved well. Vomited in the early morning of 30 th, with no ill-effects ; left hospital in 21 days (delay caused by atropine irritation) with vision $6 / 18$.

16. Female, aged 66 years. Urine normal. Left extraction with peripheral iridectomy, November 13, 1928; behaved well. Vomited once on the following day; no ill-effects. It had taken a long time to get this patient's culture clean; when the other cataract was extracted (previously) keratic precipitates were found in the eye 
after operation, and the same occurred in this eye, necessitating a prolonged stay of 7 weeks. Vision on discharge, $6 / 9$.

17. Female, aged 70 years. Urine normal. Right extraction with complete iridectomy, January 3, 1929. Behaviour at operation was exceedingly bad, the patient squeezing hard; she vomited immediately on return to the ward. She was a very restless patient, and had bouts of sneezing during the 3 days following operation; there were, however, no ill-effects to the eye. She became quite mentally deranged, and although discharged in routine time, vision could not be taken.

Note.--It is, I think, justifiable to exclude from this list Nos. 4 and 6 , since the vomiting in these cases evidently had the very slightest connection, if any, with the operation for cataract.

The following facts emerge from this list :-

1. In 141 cases of cataract operation, vomiting occurred in $\mathbf{1 5}$ - a proportion of 10.6 per cent.

2. Of these 15 cases of vomiting, 12 were female patients-a proportion of 80 per cent.

3 . In the 15 cases, ill-effects to the operated eye as an apparent result of the vomiting occurred in 5 cases-a proportion of 33.3 per cent. Actual prolapse of iris occurred in 2 cases-a proportion of 13.3 per cent.

4. In the majority of cases, when vomiting occurs it does so within 3 days of operation.

It is important to note that of the 141 cases under consideration, 10 of them-i.e., 7.1 per cent.-had a prolapse of the iris in the days immediately following operation for no discoverable reason. Of these, 7, or 70 per cent., were female patients. Finally, during the period under review, some 20 patients were, by way of experiment, given the ordinary hospital breakfast on the morning of operation - which includes tea and bread and butter $a d$ lib., and a boiled egg. In none of these cases did vomiting occur, and no disadvantage was seen to accrue from the practice-indeed, it would seem that extra comfort, from which usually follow more confidence and better behaviour, is insured for the patient by the avoidance of the more rigid dietary.

Some important conclusions may be drawn from the above data. In the first place it appears that vomiting after cataract extraction is a far less serious occurrence than is generally supposed, and that it is very rare for any harm to happen to the operated eye as a result. This is of great interest considering the effort necessarily involved, especially as vomiting usually occurs before the edges of the incision have had time to become at all firmly united. It 
would seem that there is little to gain from excessively rigid treatment of patients after extraction in the direction of forbidding movement of any kind ; for every patient who has a prolapse as an apparent result of vomiting there are five who suffer the same misfortune for no apparent reason-all being otherwise under the same conditions. The high proportion of female patients in whom prolapse of the iris occurs after extraction, both apparently spontaneously and after vomiting, is of interest, and may indicate a lack of tone in the iris of these as compared with male patients.

On the other hand, the more frequent occurrence of vomiting in female patients may afford a clue to the cause of this disorder, which is usually considered to be merely a matter of posture, the enforced lying in the unnatural supine position causing unusual stresses to be set up in the stomach wall, which in their turn cause vomiting. The female predominance may, however, indicate that it is a purely nervous phenomenon, occurring in the more apprehensive and " highly-strung " sex. Alternatively, the constant use of purgatives by females is a well-known fact; it is reasonable to assume that their use causes a chronic irritation of the gastric and duodenal mucosa, which in a time of exceptional strain reveals itself in vomiting. The familiar occurrence of vomiting after squint operations is probably due to the passive movement of the ocular muscles and their retention in an unnatural position; such retention does not, however, occur after cataract operations, and it is not likely that the small amount of passive movement which sometimes (but not always, especially in obedient patients) occurs during operation for cataract would warrant an explanation on these lines.

The final conclusion which may be drawn from these observations is also important. No useful purpose appears to be served by the comparative starvation of patients before operation for cataract -indeed, the reverse may well be the case, for there is no doubt that the withholding of a usual meal from a patient is not conducive to a feeling of bien-être or even of resignation, whereas these feelings would certainly tend to help the patients' behaviour on the operating table, making them less apprehensive, and more passive and obedient. The number of patients operated upon after a full breakfast is not enough to justify any definite conclusions being drawn; but enough has been done to encourage one to continue the experiment, since it is proved that comparative starvation does not prevent vomiting, nor in any case did the partaking of the usual meal cause it. 